\title{
Nonextraction Treatment of Class I Malocclusion having Anterior Crowding and Multiple Canine Impactions
}

\author{
${ }^{1}$ Chetna D Sirsat, ${ }^{2}$ Vivek Patni, ${ }^{3}$ Prateek Daga, ${ }^{4}$ Divij Joshi
}

\begin{abstract}
Canine impaction is a condition wherein the tooth is embedded in the alveolus and is locked in by bone, teeth, or other structures, leading to difficulty in eruption. In this study, we present a case report of a 15-year-old female patient with a straight profile, class I skeletal and dental relationship, over retained deciduous teeth, severe anterior crowding in both the arches, and impacted canine in maxillary arch on both the sides and in mandibular arch on the right side. Extraction of deciduous teeth was done prior to fixed appliance therapy. After leveling and alignment using fixed appliance, surgical exposure of impacted canines was done using open flap surgical technique. Canines were brought into occlusion using conventional orthodontic technique. In mandibular arch, space for lingually placed lateral incisor was created using nickel-titanium (NiTi) open coil spring. Results achieved after decrowding and getting impacted canines into normal occlusion are presented.
\end{abstract}

Keywords: Class I, Crowding, Impacted canines, Nickeltitanium open coil spring, Open flap surgical technique.

How to cite this article: Sirsat CD, Patni V, Daga P, Joshi D. Nonextraction Treatment of Class I Malocclusion having Anterior Crowding and Multiple Canine Impactions. J Contemp Dent 2017;7(3):169-173.

Source of support: Nil

Conflict of interest: None

\section{INTRODUCTION}

The second most common impacted teeth after third molars are the maxillary canine. Maxillary canines tend to have the longest developmental period, the deepest developmental zone, and the most difficult eruption path compared with the other teeth in the oral cavity. ${ }^{1}$ Surgical exposure and orthodontic guidance during eruption are commonly required for such cases. ${ }^{2}$ Incidence of maxillary canine impaction is higher in females (around $0.8-2.8 \%$ ) and are impacted more often palatally. ${ }^{3}$

\footnotetext{
${ }^{1}$ Postgraduate Student, ${ }^{2}$ Professor, ${ }^{3,4}$ Lecturer

${ }^{1-4}$ Department of Orthodontics and Dentofacial Orthopedics Mahatma Gandhi Mission's Dental College and Hospital, Navi Mumbai, Maharashtra India

Corresponding Author: Chetna D Sirsat, Postgraduate Student Department of Orthodontics and Dentofacial Orthopedics Mahatma Gandhi Mission's Dental College and Hospital, Navi Mumbai, Maharashtra, India, Phone: +919004560542, e-mail: chetnadent@yahoo.com
}

The radiographic diagnosis of position of the canine is instrumental to the orthodontist's decision to both expose and orthodontically align or to remove the impacted maxillary canine. ${ }^{4}$ Difficulty level of impacted or ectopically erupted maxillary canines depends on the position of the teeth. ${ }^{5}$ Different treatment options for treating impacted teeth are available. Surgical reposition, tooth extraction, surgical-orthodontic management, and implant replacement all have been advocated in the literature.

The aim of this article was to present a case in which a combined surgical-orthodontic management impacted canines guiding it to normal occlusion.

\section{CASE REPORT}

A 15-year-old female patient reported to the Department of Orthodontics and Dentofacial Orthopaedics with the chief complaint of forwardly placed upper front teeth. On extraoral examination, the patient had a straight profile, normal nasolabial angle, and deep mentolabial sulcus. On intraoral examination, constricted maxillary and mandibular arches, mixed dentition, bilateral class I molar relation, and unerupted permanent maxillary and right mandibular canine, crowding in both arches with lingually erupting mandibular lateral incisors, overjet of $1 \mathrm{~mm}$ and overbite of $5 \mathrm{~mm}$. The pretreatment extraoral and intraoral photographs were taken (Figs 1 and 2). The case was diagnosed as skeletal class I malocclusion with orthognathic maxilla and orthognathic mandible with impacted maxillary canines and mandibular right canine. Same-lingual, opposite-buccal technique was used to rule out the location of canines and all three were found to be placed labially. Cephalometric analysis (Table 1) confirmed diagnosis of class I skeletal base having average growth pattern and impacted canines (Fig. 3).

\section{OBJECTIVES}

- Decrowding in both maxillary and mandibular arch

- Eruption impacted canines in both arches

- Achieving correct overjet and overbite

- Maintaining class I molar relationship

\section{TREATMENT PLAN}

The treatment plan wasextraction of overretained deciduous teeth in both arches followed by fixed appliance therapy. After leveling alignment, the impacted maxillary right 

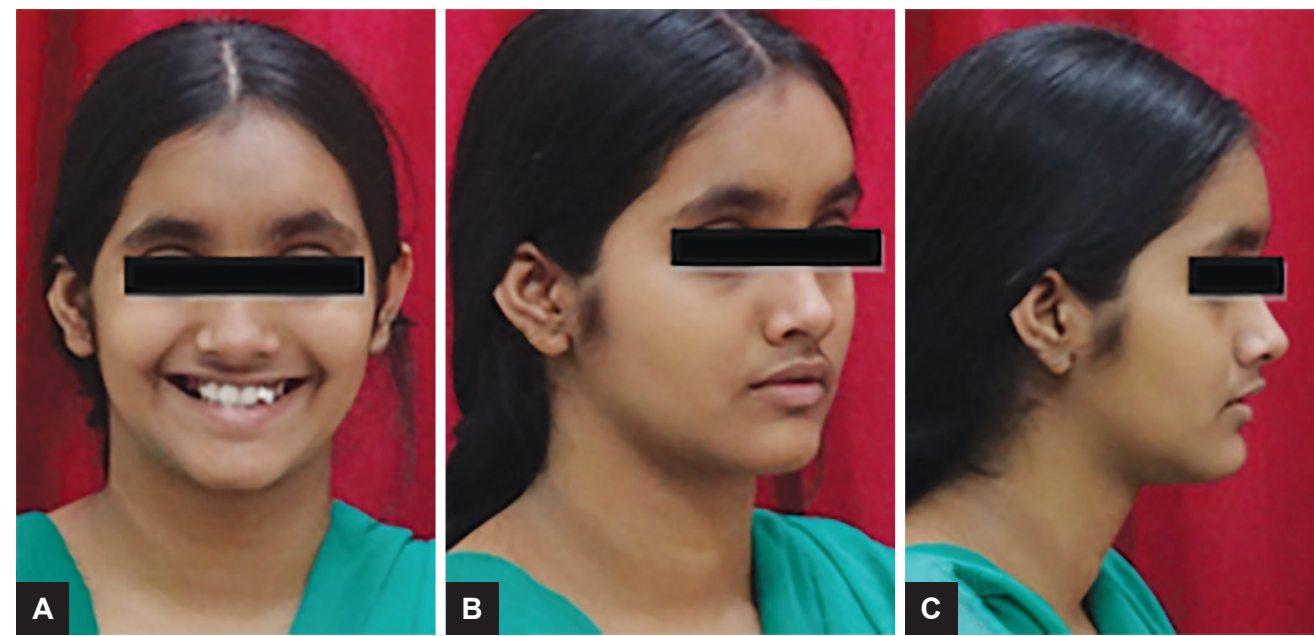

Figs $1 \mathrm{~A}$ to $\mathrm{C}$ : Pretreatment extraoral photographs
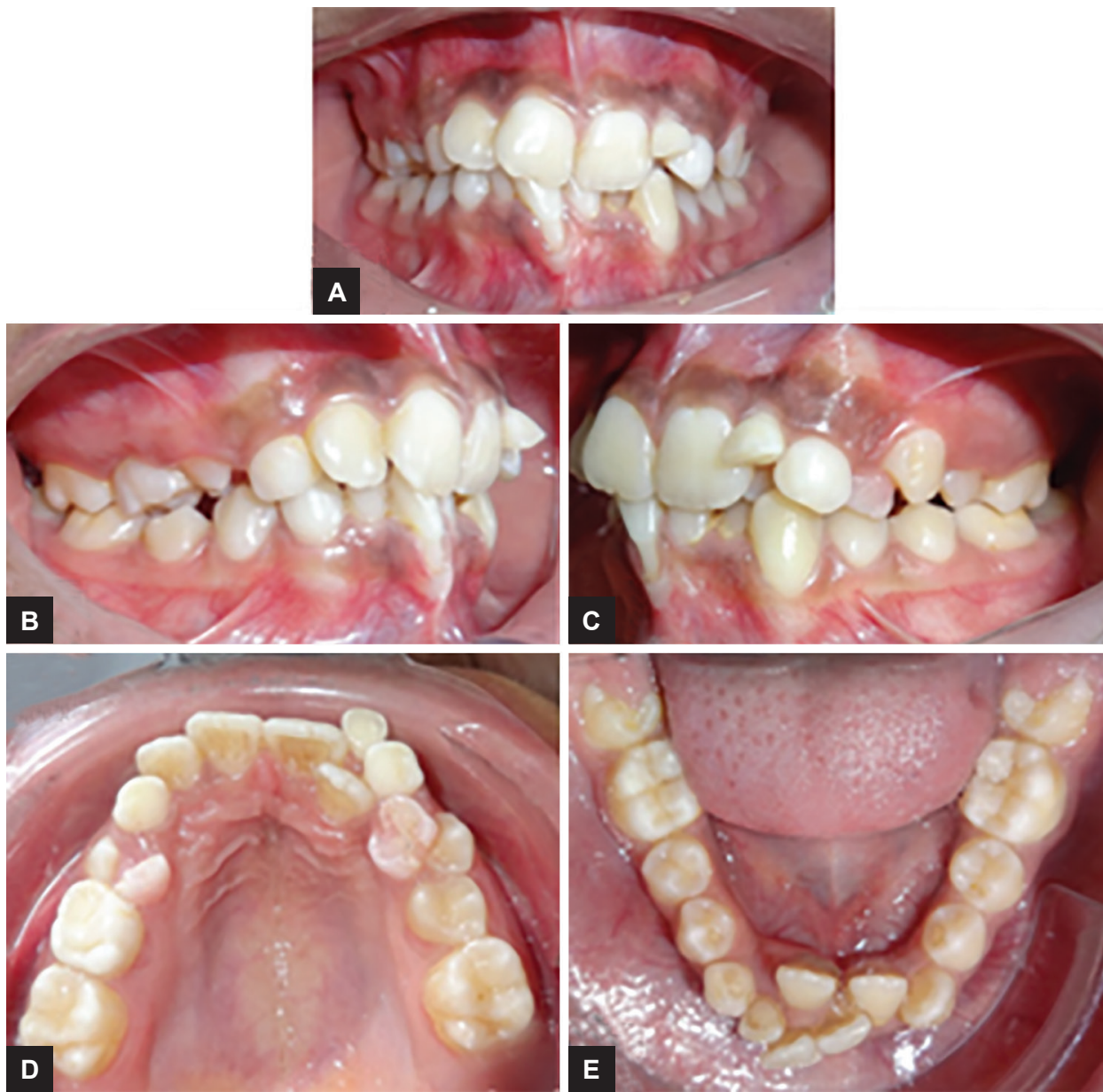

Figs $2 A$ to E: Pretreatment intraoral photographs showing mixed dentition with $53,54,55,62$, $63,64,82,83$

and left canine was surgically exposed using open flap surgical technique. Bonding attachments on exposed canine and applying traction force on canines brought it to normal occlusion followed by fixed appliance therapy. After leveling alignment, NiTi open coil spring was placed to create space for lingually placed lateral incisors. Bonding attachments on lateral incisors and traction force were applied to bring it in normal occlusion.

\section{TREATMENT PROGRESS}

All deciduous overretained teeth were extracted. Fixed appliance therapy using $0.022^{\prime \prime} \times 0.028^{\prime \prime}$ appliance with MBT prescription was used. Maxillary teeth were bonded initially for correction of overbite and creation of space for impacted maxillary canines. After that, NiTi open coil spring was used to gain sufficient space. Surgical procedure was then performed for exposure of impacted 


\begin{tabular}{ll}
\multicolumn{2}{c}{ Table 1: Cephalometric values } \\
\hline Pre-treatment & \\
\hline SNA & $78^{\circ}$ \\
SNB & $80^{\circ}$ \\
ANB & $+2^{\circ}$ \\
Wits appraisal & $0.5 \mathrm{~mm}$ \\
IMPA & $90^{\circ}$ \\
GoGn to SN & $35^{\circ}$ \\
FMA & $25^{\circ}$ \\
U1 to NA & $23^{\circ} / 4 \mathrm{~mm}$ \\
L1 to NB & $24^{\circ} / 4 \mathrm{~mm}$ \\
\hline
\end{tabular}

canine using open flap technique (Fig. 4). Begg's brackets were bonded on the exposed canine and elastic threads were used to apply traction on impacted canines. Once the canines were in sufficient occlusion, NiTi wires were used for its alignment. After 11 months of active treatment and overbite correction was achieved, lower arch bonding was performed. Sufficient spaces were created for the lower right and both lateral incisor using NiTi open coil spring (Fig. 5). Once sufficient spaces were achieved, lateral incisors were brought into alignment using NiTi wires. Finishing and detailing were performed on heavy archwire for achieving class I molar and class I canine relationship bilaterally. Total treatment duration was 18 months. Posttreatment results were satisfactory (Fig. 6).
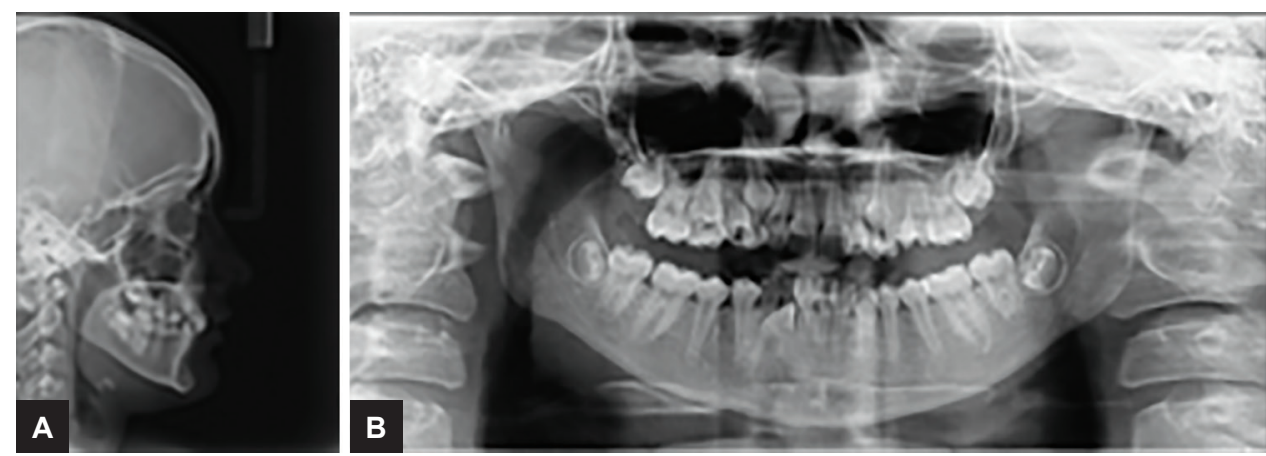

Figs 3 A and B: Lateral cephalogram and orthopantomogram
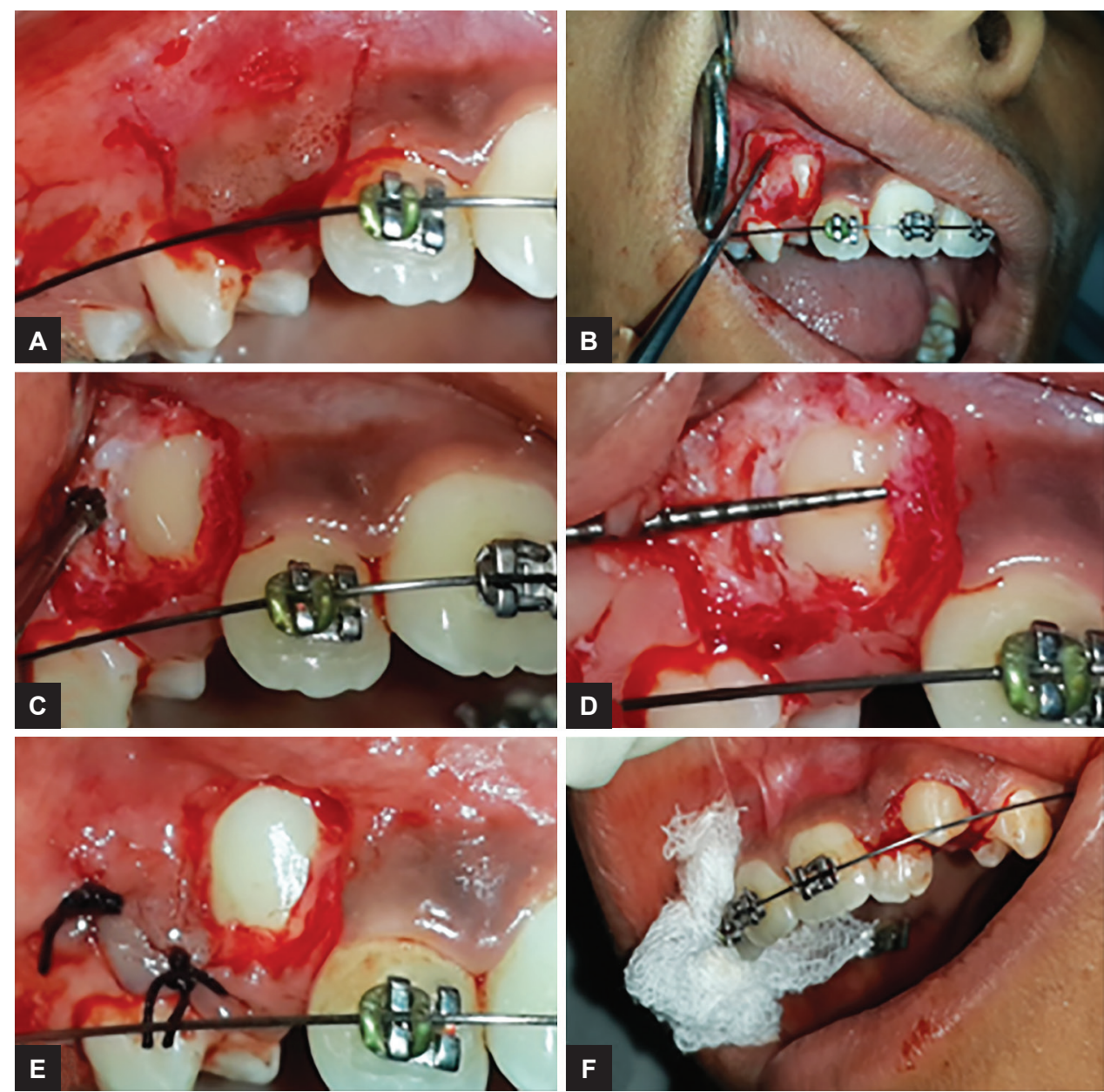

Figs 4A to F: Surgical exposure of impacted canines using open flap surgical technique 

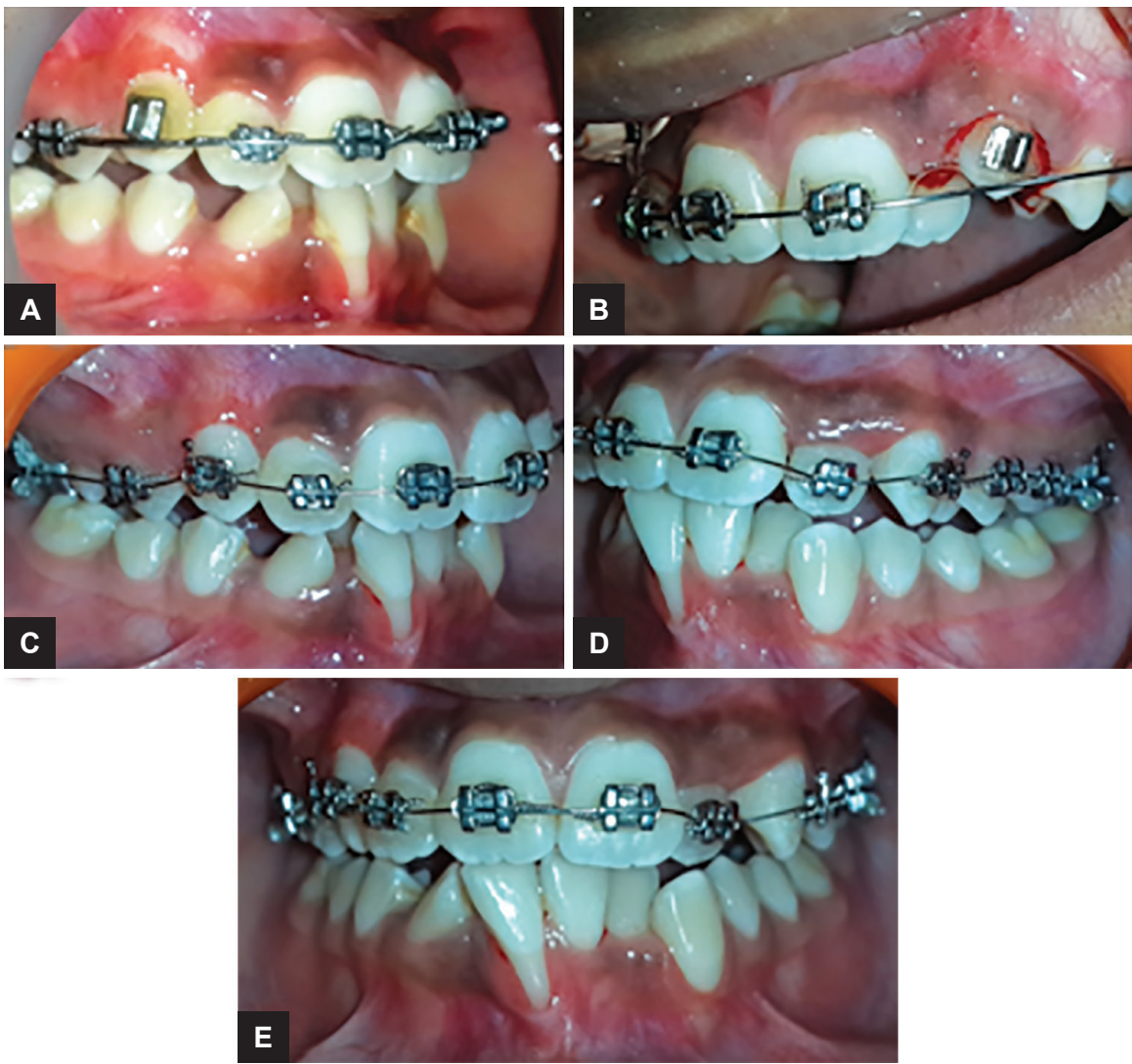

Figs $5 \mathrm{~A}$ to $\mathrm{E}$ : Treatment progress
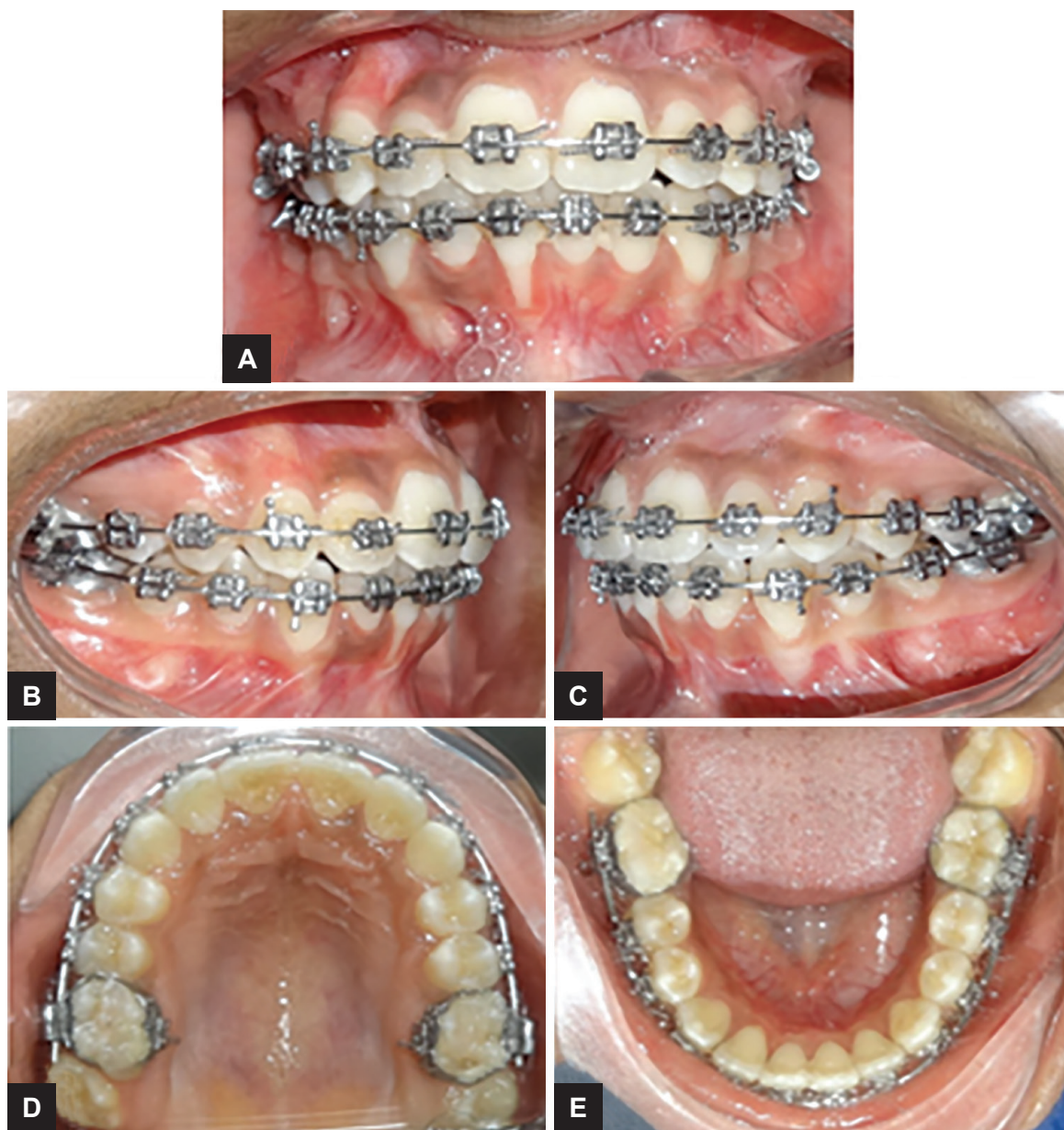

Figs $6 \mathrm{~A}$ to $\mathrm{E}$ : Posttreatment view 


\section{DISCUSSION}

Orthodontic management of impacted canine is the most widely discussed topic in literature. Level of difficulty in managing impacted tooth cases depends on position and direction of canine in arch. Fournier et $\mathrm{al}^{6}$ recommended that a labially impacted tooth in a favorable vertical position should be surgically exposed without the application of orthodontic traction in a young patient, whereas immediate traction is almost always needed in an adult patient. Labial impaction, on the contrary, is generally thought to be more difficult to manage. ${ }^{7,8}$ Studies reporting the periodontal condition of buccally impacted canines after closed eruption exposure found excellent appearance, but a decrease in the width of attached gingiva. ${ }^{9}$ Studies have directly compared open vs closed surgical outcomes in buccal canines alone, although mixed groups of palatal and buccal canines have been investigated. ${ }^{10,11}$ According to Proffit et al, ${ }^{12}$ there are three categories of problems when dealing with an impacted tooth: Surgical exposure, attachment to the tooth, and orthodontic mechanics to bring the tooth into the arch. The surgical procedure was longer in closed technique as compared with the open technique. ${ }^{13}$ In this case, open flap surgical technique is used for exposure of impacted canine.

Nickel-titanium coil springs possess high resistance to permanent deformation and have potential relatively constant delivery of force during unloading. ${ }^{14}$ In this case report, to create space for impacted canine and in-locked lateral incisors, NiTi open coil spring was used.

\section{CONCLUSION}

Early diagnosis of case and precautionary measures, such as primary teeth extraction, may prevent further complications and reduce patient treatment time, expense, and complex treatment procedures. A proper diagnosis and careful selection of orthodontic and surgical technique help to achieve successful impacted treatment of canines giving esthetically pleasant smile.

\section{REFERENCES}

1. Jacoby H. The etiology of maxillary canine impactions. Am J Orthod 1983 Aug;84(2):125-132.

2. Bass TB. Observations on the misplaced upper canine tooth. Dent Pract Dent Rec 1967 Sep;18(1):25-33.

3. Ericson S, Kurol J. Resorption of incisors after ectopic eruption of maxillary canines: a CT study. Angle Orthod 2000 Dec;70(6):415-423.

4. Stivaros N, Mandall N. Radiographic factors affecting the management of impacted upper permanent canines. J Orthod 2000 Jun;27(2):169-173.

5. Yadav S, Chen J, Upadhyay M, Jiang F, Roberts WE. Comparison of the force systems of 3 appliances on palatally impacted canines. Am J Orthod Dentofacial Orthop 2011 Feb;139(2):206-213.

6. Fournier A, Turcotte JY, Bernard C. Orthodontic considerations in the treatment of maxillary impacted canines. Am J Orthod 1982 Mar;81(3):236-239.

7. Von der Heydt K. The surgical uncovering and orthodontic positioning of unerupted maxillary canines. Am J Orthod 1975 Sep;68(3):256-276.

8. Lewis PD. Preorthodontic surgery in the treatment of impacted canines. Am J Orthod 1971 Oct;60(4):382-397.

9. Kohavi D, Zilberman Y, Becker A. Periodontal status following the alignment of buccally ectopic maxillary canine teeth. Am J Orthod 1984 Jan;85(1):78-82.

10. Crescini A, Nieri M, Buti J, Baccetti T, Pini Prato GP. Orthodontic and periodontal outcomes of treated impacted maxillary canines. Angle Orthod 2007 Jul;77(4):571-577.

11. Crescini A, Nieri M, Buti J, Baccetti T, Mauro S, Prato GP. Short- and long-term periodontal evaluation of impacted canines treated with a closed surgical-orthodontic approach. J Clin Periodontol 2007 Mar;34(3):232-242.

12. Proffit, WR.; Fields, HW.; Sarver, DM. Contemporary orthodontics. 4th ed. St. Louis (MO): Mosby Elsevier; 2007.

13. Londhe SM, Kumar P, Datana S, Kotwal A, Saxena V. Guided tooth eruption: comparison of open and closed eruption techniques in labially impacted maxillary canines. J Dent Res Rev 2014;1(3):148-151.

14. Agarwal DK, Razdan A, Bhattarchya P, Agarwal A, Gupta A. Comparative study of orthodontic coil springs. J Indian Orthod Soc 2011;45(4):160-168. 